\title{
Does GSK-3 provide a shortcut for PI3K activation of Wnt signalling? Daniel Voskas ${ }^{1}$, Ling S Ling ${ }^{2}$ and James R Woodgett ${ }^{1,2 *}$
}

Addresses: ${ }^{1}$ Samuel Lunenfeld Research Institute, Mount Sinai Hospital, 600 University Avenue, Toronto, ON, M5G 1X5, Canada; ${ }^{2}$ Department of Medical Biophysics, University of Toronto, 27 King's College Circle, Toronto, ON, M5S 1A1, Canada

* Corresponding author: James R Woodgett (woodgett@lunenfeld.ca)

Fl000 Biology Reports 2010, 2:82 (doi:10.34I0/B2-82)

This is an open-access article distributed under the terms of the Creative Commons Attribution-Non Commercial License (http://creativecommons.org/licenses/by-nc/3.0/legalcode), which permits unrestricted use, distribution, and reproduction in any medium, provided the original work is properly cited. You may not use this work for commercial purposes.

The electronic version of this article is the complete one and can be found at: http://fl000.com/reports/b/2/82

\begin{abstract}
Glycogen synthase kinase-3 (GSK-3) is a well-established downstream component of the phosphatidylinositol 3-kinase (PI3K) signalling pathway but is also a key enzyme in negatively regulating the canonical Wnt/ $\beta$-catenin signalling pathway. Several recent studies argue that PKB (protein kinase B)mediated inhibition of GSK-3 leads to $\beta$-catenin accumulation, but whether cross-talk actually exists between these two pathways is controversial. To elucidate the mechanisms of shared signalling components, further studies taking into account different components of the PI3K signalling pathway and different pools of GSK-3 or $\beta$-catenin are required.
\end{abstract}

\section{Introduction and context}

Glycogen synthase kinase-3 (GSK-3) is a constitutively active and ubiquitously expressed serine/threonine kinase [1]. In addition to playing a well-defined role in suppressing the canonical Wnt/ $\beta$-catenin signalling pathway [2,3], it functions in Hedgehog, Notch, and several growth factor signalling pathways [4]. Large amounts of $\beta$-catenin typically are associated with cadherin complexes at the plasma membrane of adherent cells. However, in the absence of Wnt signalling, GSK-3 phosphorylates cytosolic $\beta$-catenin within a complex that includes adenomatous polyposis coli, Axin-1, casein kinase-1 (CK-1), and other proteins and targets it for ubiquitinmediated degradation (Figure 1a). In this manner, very low levels of non-cadherin-associated $\beta$-catenin are maintained in the cell. Upon Wnt binding to Frizzled receptors and low-density lipoprotein receptor-related protein (LRP) co-receptors and subsequent engagement of the intracellular protein Dishevelled, the destruction complex is disrupted, GSK-3 and CK-1 activities are diverted to LRP co-receptors at the membrane, and cytoplasmic $\beta$-catenin avoids phosphorylation. As a result, $\beta$-catenin accumulates and enters the nucleus to regulate gene expression via binding to the TCF/LEF (T-cell factor/lymphoid enhancerbinding factor) DNA-binding proteins (Figure 1b).
Physiological levels of GSK-3 do not limit the capacity of the destruction complex to mediate $\beta$-catenin degradation; only a small percentage $(<10 \%)$ of the total GSK-3 in the cell is associated with Axin and engaged in canonical Wnt signalling [5,6]. Other pools of GSK-3 are additionally used in several other pathways. Upon insulin stimulation and consequent phosphatidylinositol 3-kinase (PI3K) activation, for example, the serine/ threonine kinase protein kinase $\mathrm{B}(\mathrm{PKB}) /$ Akt phosphorylates GSK-3 and negatively regulates its kinase activity (Figure 1c) [7]. A similar mechanism of negative regulation of GSK-3 has been demonstrated in other growth factor pathways [8-11]. Regulation of $\beta$-catenin has also been demonstrated in many of these pathways [8-12]. However, the direct convergence of Wnt and growth factor pathways on $\beta$-catenin regulation remains a controversial topic of discussion.

Several human cancers tend to involve separate mutations of both pathways [13]. If PI3K activation were sufficient to activate Wnt signalling, why would additional mutations that lead to $\beta$-catenin stabilization be needed? Several studies have also shown that growth factor stimulation that leads to GSK-3 inhibition through PI3K signalling does not result in stabilization 
Figure I. GSK-3 in Wnt and growth factor signalling pathways

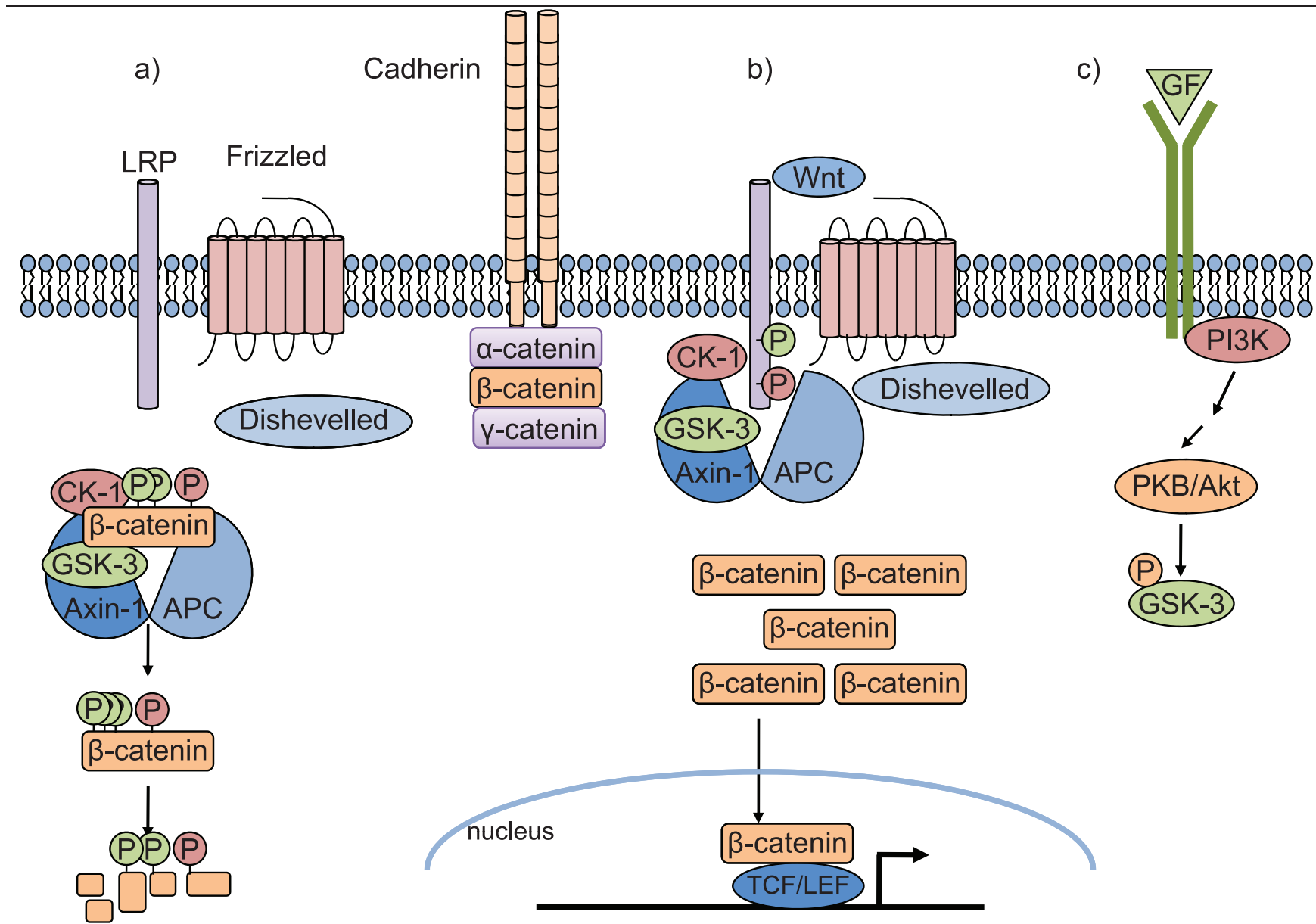

(a) In the absence of Wnt signalling, the destruction complex comprised of APC, Axin-I, CK-I, and GSK-3 promotes the phosphorylation and subsequent ubiquitin-mediated degradation of $\beta$-catenin. (b) Upon Wnt stimulation, Dishevelled is engaged, the destruction complex is disrupted, and CK-I and GSK-3 activities are diverted to LRP at the cell membrane. Unphosphorylated $\beta$-catenin may accumulate and enter the nucleus to regulate gene expression upon binding to TCF/LEF DNA-binding proteins. (c) Upon growth factor stimulation, activation of the PI3K signalling cascade leads to PKB-mediated phosphorylation of GSK-3 and inhibition of its kinase activity. APC, adenomatous polyposis coli; CK-I, casein kinase-I; GF, growth factor; GSK-3, glycogen synthase kinase-3; TCF/LEF, T-cell factor/lymphoid enhancer-binding factor; LRP, low-density lipoprotein receptor-related protein; PI3K, phosphatidylinositol 3-kinase; PKB, protein kinase $B$.

of $\beta$-catenin in the cell [14-16]. Furthermore, GSK-3 molecules that have mutations in the PKB phosphorylation sites and thus that are insensitive to inhibition by PI3K signalling are still inhibited by Wnt signalling [15-17]. It would appear that, although PI3K and Wnt signalling pathways share a core regulatory protein, the insulation of these pathways is sufficient to prevent crosstalk [18]. As demonstrated by Ng and colleagues [16], Axin may shield the associated GSK-3 within the destruction complex from protein kinases (such as PKB) that otherwise would phosphorylate and inactivate GSK-3. Although GSK-3 that is not directly associated with the complex may still be phosphorylated and inhibited, sufficient levels remain bound to the Axin complex to suppress the accumulation of $\beta$-catenin. It should be noted that chemical inhibitors of GSK-3 affect all GSK-3 molecules within a cell. Hence, use of such reagents eliminates any selectivity gained by compartmentalization of the kinase. This is also true for genetic knockout or RNAi (RNA interference) suppression of each of the two isoforms (GSK-3 $\alpha$ and $-\beta$ ), although suppression must exceed $75-80 \%$ to have an impact on $\beta$-catenin [17].

\section{Major recent advances}

A recent report by Maes and colleagues [11] describes the effects of induction of vascular endothelial growth factor (VEGF) overexpression in the osteo-chondroprogenitor cells of adult mice. VEGF overexpression caused vascular 
defects, bone marrow fibrosis, hematological abnormalities, and increased bone mass, similar to the bone phenotype observed upon $\beta$-catenin overexpression in the osteo-progenitor cells of mice $[19,20]$. VEGF overexpression correlated with increased PI3K signalling via VEGFR-2 (VEGF receptor-2), leading to enhanced GSK-3 phosphorylation, and the authors also observed $\beta$-catenin stabilization. These results support the idea that receptor tyrosine kinase-mediated growth factor signals act through PI3K to induce $\beta$-catenin. However, there are other explanations. Accumulation of $\beta$-catenin in the mouse tissues could be due to indirect activation of conventional Wnt signalling through induction of Wnt ligands or modulators. Although the authors show that $\beta$ catenin induction is sensitive to infusion of the PI3K antagonist wortmannin in the VEGF-expressing mice, this does not exclude an indirect pathway. Another possible mechanism is suggested by the known effect of VEGF promotion of vascular permeability, a process that is preceded by VEGF-dependent vascular endothelialcadherin (VE-cadherin) phosphorylation and dissolution of the VE-cadherin complex comprised of adherens junction proteins p120, $\beta$-catenin, plakoglobin, and $\alpha$-catenin [21]. Thus, excess levels of cytosolic $\beta$-catenin released from the membrane compartment, together with increased stress on the destruction complex, may contribute to VEGF-mediated effects on $\beta$-catenin stabilization. Furthermore, nuclear localization of $\beta$-catenin has been reported to be promoted by $\mathrm{PKB}$ phosphorylation of Ser552 [22]. Clearly, it is not trivial to exclude alternative or indirect effects but it is somewhat easier to assume that the correlation between PI3K-induced inhibition of GSK-3 and accumulation of $\beta$-catenin is actually a direct linkage.

\section{Future directions}

Insulation mechanisms play critical roles in permitting shared signalling components between pathways yet maintain the integrity of these pathways and resultant biological processes. Under normal circumstances, signalling specificity appears well insulated and can withstand precise experimental pressure. However, these mechanisms may be overwhelmed by unnatural genetic and chemical perturbation or by disease mutations. Furthermore, the insulating mechanisms may not be relevant in all tissues or cell types. For example, both PKB and GSK-3 interact with the scaffold protein DISC-1 (disrupted-in-schizophrenia-1) in neurons and this protein, when overexpressed, has been shown to lead to accumulation of $\beta$-catenin and subsequent signalling [23-25]. It remains to be seen whether DISC-1 might mediate cross-talk between the PI3K and Wnt pathways in a more biologically relevant context since DISC-1 protein levels do not change significantly and the amount of GSK-3 bound by DISC-1 is only a small fraction of the cellular total - similar to the amount associated with Axin - and therefore is unlikely to be competitive. The small GTPase Cdc42 (cell division control protein-42 homolog), through its regulation of the PAR/aPKC (partitioning defective/atypical protein kinase $\mathrm{C}$ ) complex, has been proposed to inhibit GSK-3 and stabilize $\beta$-catenin in the skin [26]. Activation of Wnt signalling by aPKC raises questions not unlike those associated with the effect of PKB on GSK-3 and $\beta$-catenin but also raises the possibility that PI3K may activate Cdc42 $[27,28]$ and impinge on Wnt signalling in a PKBindependent manner. To definitively address the mechanisms and circumstances by which PI3K or other components of this pathway might impact $\beta$-catenin regulation, future experiments will need to be conducted with cells or tissues that possess depleted levels of GSK-3 or $\beta$-catenin and thus exhibit increased sensitivity to upstream manipulation of growth factor or Wnt signalling. Under these sensitized conditions, cross-talk may be more biologically relevant and detectable. Likewise, if such experiments fail to demonstrate interplay, there may be greater appreciation of the compartmentalization of signalling events under physiological conditions. Generation of cell lines in which elements of the PI3K pathway can be rapidly activated (e.g., PKB-estrogen receptor fusions) should allow investigators to evaluate whether $\beta$-catenin levels are induced within the expected time frame $(\beta$-catenin accumulation requires $>30 \mathrm{~min}$ utes). The potential for different pools of GSK-3 or $\beta$-catenin to supplement each other in the cell must also be carefully evaluated in such experiments. Importantly, the dynamics of any observed changes must be taken into consideration to exclude one pathway from leading to changes in the levels of agonists and antagonists of another pathway such as through transcriptional regulation or micro-RNA expression. There are many examples of shared components in signalling pathways with little consideration of distinct pools or mechanisms to chaperone and isolate fractions of these molecules. Often, the simplest and most direct path is not taken in biology, leading to erroneous assumptions and conclusions. Indeed, understanding why a more convoluted route has been chosen can reveal new discoveries and previously overlooked components.

\section{Abbreviations}

aPKC, atypical protein kinase C; Cdc42, cell division control protein-42 homolog; CK-1, casein kinase-1; DISC-1, disrupted-in-schizophrenia-1; GSK-3, glycogen synthase kinase-3; LRP, low-density lipoprotein receptorrelated protein; PI3K, phosphatidylinositol 3-kinase; PKB, protein kinase $\mathrm{B}$; VE-cadherin, vascular endothelialcadherin; VEGF, vascular endothelial growth factor. 


\section{Competing interests}

The authors declare that they have no competing interests.

\section{Acknowledgments}

The authors acknowledge funding by the Canadian Institutes of Health Research (CIHR) Operating Grant FRN 74711 (to JRW) and a Heart and Stroke Foundation (Ontario, Canada) postdoctoral fellowship (to DV).

\section{References}

I. Woodgett JR: Molecular cloning and expression of glycogen synthase kinase-3/factor A. EMBO J 1990, 9:243I-8.

2. van Amerongen $R$, Nusse $R$ : Towards an integrated view of Wnt signaling in development. Development 2009, I36:3205-14.

3. MacDonald $B T$, Tamai $K$, He $X$ : Wnt/3-catenin signaling: components, mechanisms, and diseases. Dev Cell 2009, 17:9-26.

4. Hur EM, Zhou FQ: GSK3 signalling in neural development. Nature Rev Neuro 2010, I I:539-5I.

5. Lee E, Salic A, Kruger R, Heinrich R, Kirschner MW: The roles of $A P C$ and Axin derived from experimental and theoretical analysis of the Wnt pathway. PLOS Biol 2003, I:EIO.

FI000 Factor 9

Evaluated by Randall Moon 24 Oct 2003, Jeffrey Axelrod 30 Oct 2003

6. Benchabane $\mathrm{H}$, Hughes EG, Takacs CM, Baird JR, Ahmed Y: Adenomatous polyposis coli is present near the minimal level required for accurate graded responses to the Wingless morphogen. Development 2008, I35:963-7I.

7. Cross DA, Alessi DR, Cohen P, Andjelkovich M, Hemmings BA: Inhibition of glycogen synthase kinase- 3 by insulin mediated by protein kinase B. Nature 1995, 378:785-9.

8. Ishibe S, Haydu JE, Togawa A, Marlier A, Cantley LG: Cell Confluence Regulates Hepatocyte Growth Factor-Stimulated Cell Morphogenesis in a beta-Catenin-Dependent Manner. Mol Cell Biol 2006, 26:9232-43.

9. Gu D, Yu B, Zhao C, Ye W, Lv Q, Hua Z, Ma J, Zhang Y: The effect of pleiotrophin signaling on adipogenesis. FEBS Letters 2007, 58 I:382-8.

10. Kobielak K, Stokes N, de la Cruz J, Polak L, Fuchs E: Loss of a quiescent niche but not follicle stem cells in the absence of bone morphogenetic protein signaling. PNAS 2007, 104:10063-8.

II. Maes C, Goossens S, Bartunkova S, Drogat B, Coenegrachts L, Stockmans I, Moermans K, Nyabi O, Haigh K, Naessens M, Haenebalcke L, Tuckermann JP, Tjwa M, Carmeliet P, Mandic V, David JP, Behrens A, Nagy A, Carmeliet G, Haigh J]: Increased skeletal VEGF enhances $\beta$-catenin activity and results in excessively ossified bones. EMBO J 2010, 29:424-4I.

12. He XC, Zhang J, Tong WG, Tawfik O, Ross J, Scoville DH, Tian Q, Zeng $X$, He X, Wiedemann LM, Mishina Y, Li L: BMP signaling inhibits intestinal stem cell self-renewal through suppression of Wnt-beta-catenin signalling. Nat Gen 2004, 36: I I 17-21.

13. Wu R, Hendrix-Lucas N, Kuick R, Zhai Y, Schwartz DR, Akyol A, Hanash S, Misek DE, Katabuchi H, Williams BO, Fearon ER, Cho KR: Mouse model of human ovarian endometrioid adenocarcinoma based on somatic defects in the Wnt/beta-catenin and PI3K/Pten signaling pathways. Cancer Cell 2007, II:32I-33.

FI000 Factor 8

Evaluated by Patrice Morin 26 Jun 2007
14. Ding VW, C RH, McCormick F: Differential regulation of glycogen synthase kinase $3 \beta$ by insulin and Wnt signaling. j Biol Chem 2000, 275:32475-8I.

15. McManus EJ, Sakamoto K, Armit LJ, Ronaldson L, Shpiro N, Marquez R, Alessi DR: Role that phosphorylation of GSK3 plays in insulin and Wnt signalling defined by knockin analysis. EMBO J 2005, 24:157|-83.

16. Ng SS, Mahmoudi T, Danenberg E, Bejaoui I, de Lau W, Korswagen HC, Schutte M, Clevers H: Phosphatidylinositol 3-kinase signaling does not activate the Wnt cascade. J Biol Chem 2009, 284:35308-13.

17. Doble BW, Patel S, Wood GA, Kockeritz LK, Woodgett JR: Functional redundancy of GSK-3 $\alpha$ and GSK-3 $\beta$ in $W n t / \beta-$ catenin signaling shown by using an allelic series of embryonic stem cell lines. Dev Cell 2007, I 2:957-7I.

18. McNeill H, Woodgett JR: When pathways collide: collaboration and connivance among signalling proteins in development. Nature Rev Mol Cell Biol 2010, II:404-I3.

19. Glass DA, Bialek P, Ahn JD, Starbuck M, Patel MS, Clevers H, Taketo MM, Long F, McMahon AP, Lang RA, Karsenty G: Canonical Wnt signaling in differentiated osteoblasts controls osteoclast differentiation. Dev Cell 2005, 8:75I-64.

20. Rodda SJ, McMahon AP: Distinct roles for Hedgehog and canonical Wnt signaling in specification, differentiation and maintenance of osteoblast progenitors. Development 2006, 133:3231-44.

21. Dejana $E$, Orsenigo $F$, Lampugnani MG: The role of adherens junctions and VE-cadherin in the control of vascular permeability. J Cell Sci 2008, I 2 1:21 I5-22.

22. He XC, Yin T, Grindley JC, Tian Q, Sato T, Tao WA, Dirisina R, Porter-Westpfahl KS, Hembree M, Johnson T, Wiedemann LM, Barrett TA, Hood L, Wu H, Li L: PTEN-deficient intestinal stem cells initiate intestinal polyposis. Nat Genet 2007, 39:189-98.

23. Kim JY, Duan X, Liu CY, Jang MH, Guo JU, Pow-anpongkul N, Kang E, Song $H$, Ming GL: DISCI regulates new neuron development in the adult brain via modulation of AKT-mTOR signaling through KIAAI 21 2. Neuron 2009, 63:761-73.

24. Enomoto A, Asai N, Namba T, Wang Y, Kato T, Tanaka M, Tatsumi H, Taya S, Tsuboi D, Kuroda K, Kaneko N, Sawamoto K, Miyamoto R, Jijiwa M, Murakumo Y, Sokabe M, Seki T, Kaibuchi K, Takahashi M: Roles of disrupted-in-schizophrenia I-interacting protein girdin in postnatal development of the dentate gyrus. Neuron 2009, 63:774-87.

25. Mao Y, Ge X, Frank CL, Madison JM, Koehler AN, Doud MK, Tassa C, Berry EM, Soda T, Singh KK, Biechele T, Petryshen TL, Moon RT, Haggarty SJ, Tsai LH: Disrupted in schizophrenia I regulates neuronal progenitor proliferation via modulation of GSK3beta/beta-catenin signaling. Cell 2009, 136:1017-31.

FI000 Factor 13

Evaluated by Valera Vasioukhin 23 Mar 2009, Orly Reiner 06 Apr 2009

26. Wu X, Quondamatteo F, Lefever T, Czuchra A, Meyer H, Chrostek A, Paus R, Langbein L, Brakebusch C: Cdc42 controls progenitor cell differentiation and beta-catenin turnover in skin. Genes Dev 2006, 20:57I-85.

27. Jiménez C, Portela RA, Mellado M, Rodríguez-Frade JM, Collard J, Serrano A, Martínez-A C, Avila J, Carrera AC: Role of the PI3K regulatory subunit in the control of actin organization and cell migration. J Cell Biol 2000, I 5 I:249-62.

28. Van Keymeulen A, Wong K, Knight ZA, Govaerts C, Hahn KM, Shokat KM, Bourne HR: To stabilize neutrophil polarity, PIP3 and Cdc42 augment RhoA activity at the back as well as signals at the front. J Cell Biol 2006, 174:437-45. 